\title{
A USER-FRIENDLY DIGITAL TOOL FOR THE STRUCTURAL ASSESSMENT OF HISTORIC DOMES: THE CASE STUDY OF SAINT PETER IN ROME
}

\author{
MARCO FRANCESCO FUNARI ${ }^{1 *}$, LUIS CARLOS SILVA ${ }^{2}$, DANIEL V. OLIVEIRA \\ AND PAULO B. LOURENÇO ${ }^{1}$ \\ ${ }^{1}$ ISISE, Institute of Science and Innovation for Bio-Sustainability (IB-S) \\ University of Minho, Guimarães, Portugal \\ e-mail: marcofrancesco.funari@civil.uminho.pt,danvco@civil.uminho.pt,pbl@civil.uminho.pt \\ ${ }^{2}$ ISISE, Faculty of Engineering, Universidade Lusófona de Humanidades e Tecnologias, Lisboa, \\ Portugal \\ e-mail: luisilva.civil@gmail.com
}

Keywords: Limit Analysis, Visual Programming, Historic Masonry Domes, Nelder-Mead method

\begin{abstract}
This paper presents a digital tool for the rapid structural assessment of historic masonry domes. It is especially suited for masonry domes that present long meridian cracks, ergo each partitioned element governed by a pushing failure mode. The proposed procedure considers a Heyman's no-tension mechanical model has been implemented within a commercial user-friendly visual programming environment. The numerical approach consists of a parametric modelling of the failure mechanism and, therefore, exploring the domain of possible solutions using the theorems of the limit analysis. Hence, a heuristic search method is subsequently adopted to refine the geometry of the collapse mechanism and to compute the value of the horizontal trust. The validation of the developed approach has been achieved considering the Saint Peter's dome. As reported in the literature, the behaviour of the Saint Peter's dome gradually shifted from a rigid shell-type - stiffened by hoop stresses -, towards a pushing type of dome partitioned by long meridian cracks. The study also evaluated the structural integrity of the drum. In converse with more time-consuming and advanced methods of analysis, the present procedure allows the users to perform a structural assessment of a historic masonry dome in a fast and computationally efficient manner. The developed digital tool will be freely available from a web archive hosted by the University of Minho and, therefore, easily able to reach students, researchers and structural engineers.
\end{abstract}

\section{INTRODUCTION}

The structural assessment of historic masonry dome is still a challenge. Main difficulties are especially related to the intrinsic complexity of the mechanical behaviour of masonry, with the uncertainty when modelling the potential dome load paths and with the damage-induced anisotropy. Still, a significant number of studies can be found in the literature and include both numerical and analytical methods [1-4]. The majority of such studies address the structural 
analysis and structural safety problem of masonry domes by using a numerical model based on the Finite Element Method (FEM) [5] or Discrete Element Method (DEM)[6, 7].

In the case of FEM models, the masonry is typically modelled following a continuum approach (designated as macro-modelling) $[8,9]$ or discretizing explicitly both units and joints (designated as micro-modelling) [6]. For instance, Bacigalupo et al. [10] investigated the structural assessment of the dome and drum of the Basilica of S. Maria Assunta in Carignano. The authors developed a refined FEM model and performed non-linear quasi-static analyses. Bartoli et al. [11] developed a detailed FEM-based model to perform the structural analysis of the Brunelleschi's Dome of Santa Maria del Fiore, in which both static and dynamic types of analysis were considered. Cavagli and Gudella [12] studied the dome of the Basilica of Santa Maria degli Angeli in Assisi. Static analysis was performed by means of a FE model considering whereas material nonlinearity for the masonry has been included.

In the case of DEM models, the masonry is typically modelled as the assemblage of rigid blocks inter-connected through interfaces of a given stiffness, which enables to capture large displacement and the opening and closing of joints [13]. For instance, Boni et al. [14] proposed a DEM model to study both the effects of brick pattern and infill on the stability of masonry vaults when supports are subjected to settlements.

It is worth noting that such methods require a large set of input parameters and can be both time-consuming and computationally expensive, especially when trying to model collapse. Hence, powerful analytical tools based on the theorems of the limit analysis can be an appropriate alternative. The main advantage of limit analysis approaches is that require less knowledge of the mechanical behaviour of materiats and are, thercfore, more practical. Anselini
et al. [15] proposed a computer program based on the static theorem of the limit analysis that
demands, only, an a-priori discretization of the dome in macroblocks. Casapulla et al. [16]
developed a novel digital tool to design semi-circtlar masonry arches composed of interlocking
blocks. Recently, Funari et al. [17] proposed a new digital tool aimed to parametrize the geometrical variables that characterize the failure mechanism and compute the load multiplier

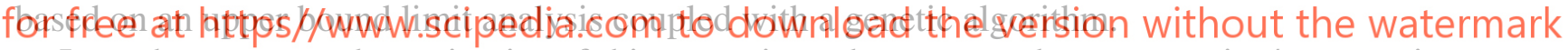

In such a context, the main aim of this paper is to demonstrate how generative/parametric modelling is a useful tool for the structural assessment of historic masonry domes. The parametric modelling of the failure mechanism allows the user to explore the domain of possible solutions using the upper bound method of the limit analysis. Then, a heuristic solver based on the Nelder-Mead method [24] is used to refine the geometry of the failure mechanism and obtain the value of the minimum horizontal thrust of the dome. The proposed methodology has been all integrated within the commercial visual programming environment offered by Rhinoceros3D + Grasshopper. The program appears easy to understand and might be used by both students and structural engineers. Unlike more advanced methods of analysis, the proposed algorithm is integrated into a user-friendly environment and allows us to perform a quick structural assessment of masonry domes. The paper is organised as follows: section 2 included the theoretical aspects of the proposed methodology and its implementation; section 3 briefly describes the selected case study; section 4 reports the obtained results; and finally, the main conclusions are discussed in section 5 . 


\section{METHODOLOGY: THE COMPUTATION OF THE MINIMUM THRUST OF MASONRY DOMES: THE KINEMATIC APPROACH}

Masonry domes tend to crack due to the low tensile strength that masonry hoop rings typically present. Hence, a diffused type of cracking along the meridian lines is observed. As extensively reported in the literature [18], the number of these cracks is not easily detectable but only one is sufficient to change the structural behaviour of the domes, i.e. from a membrane type of behaviour to a pushing dome [19].

In this framework, the computation of the minimum thrust following a static or kinematic limit-based approach is a relevant task [18]. The static approach traces the statically admissible funicular curves of the load. In the incipient collapse state, the pressure curve passes by the extrados of the key section, whereas a rotational hinge is supposed to appear. The pressure curve continues running inside the dome's thickness skimming the intrados in a point in which the second hinge appears. Yet, due to computational convenience, the present paper adopts a kinematic approach. In particular, the formulation by Como [18] has been assumed to build the digital analysis tool.

The application of the kinematic approach is based on the proper positioning of hinges to allow horizontal sliding of the dome at its springing. According to [18], the first hinge has to be placed at the extrados of the key section. In converse, the second hinge is placed at the intrados of the dome, but its position over the latter is assumed to be a variable of the mathematical problem $((h))$. The minimum value of the thrust can be computed by solving the

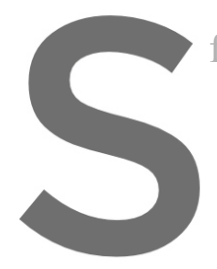

following optimization
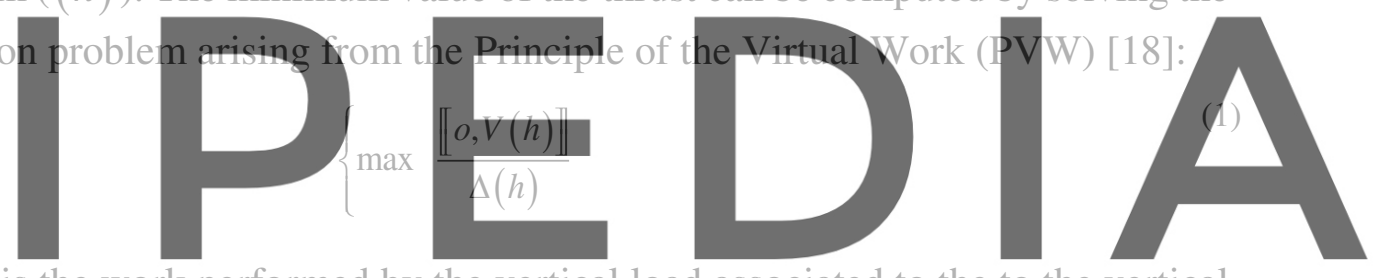

where $\| o, V(h) \rrbracket$ is the work performed by the vertical load associated to the to the vertical

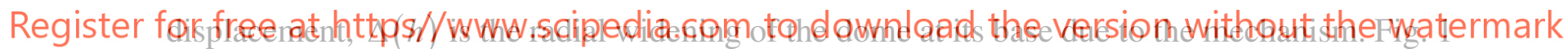

\section{shows different positions $(h)$ for the hinge along the intrados of the dome. When the horizontal}

thrust assumes the maximum value, it means that the pressure curve is inside the thickness of the dome and it is tangent to the intrados at the point $(h)$. The parametrization of the collapse mechanism is achieved by writing a generative algorithm using Grasshopper's component. The same algorithm integrates the capability to define the horizontal thrust and the numerical algorithm to compute the safety factor of the drum/attic/buttresses system. This approach allows the user to have full control of the problem and to visualize, at the same time and in an interactive fashion, the collapse mechanism. In this work and aiming the solution of the optimization problem reported in Eq. (1), the Nelder-Mead method has been adopted [20]. The Nelder-Mead iterative method is commonly applied to find the minimum or maximum of an objective function in a multidimensional space. It is a direct search method (based on function comparison) and is often applied to nonlinear optimization problems for which derivatives may not be known. Figure 2 represents a synoptic representation of the proposed methodology that has been implemented in the visual programming environment offered by Rhinoceros3D + Grasshopper. 


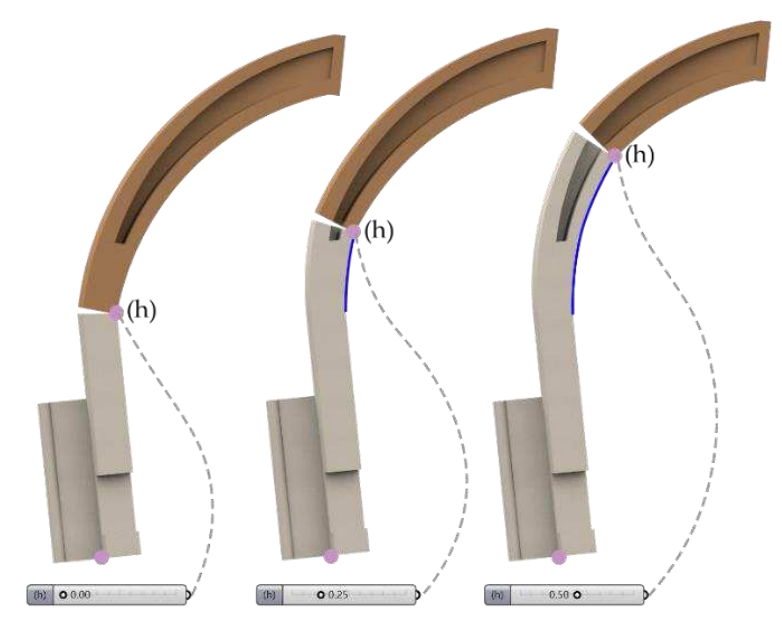

Figure 1: Parametrization of the collapse mechanism.

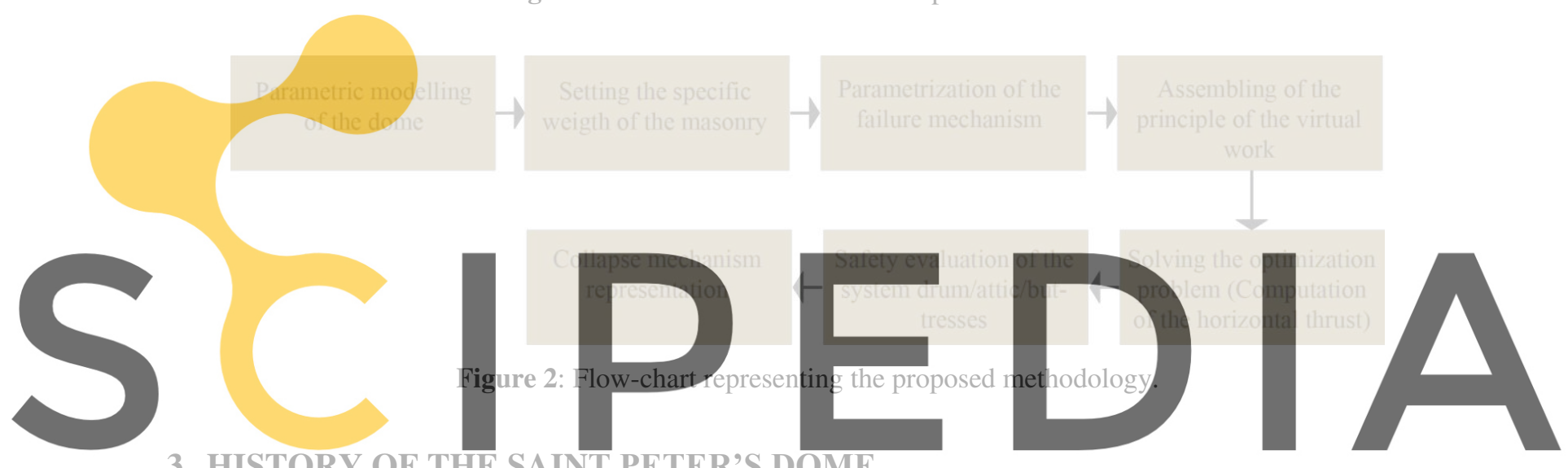

3 HISTORY OF THE SAINT PETER'S DOME

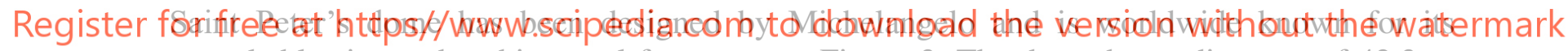
remarkable size and architectural features, see Figure 3. The dome has a diameter of $42.3 \mathrm{~m}$ and it is formed by two interconnected shells stiffened by 16 ribs. The thickness of the internal and external shells is $2.0 \mathrm{~m}$ and $1.0 \mathrm{~m}$ approximately, whereas the total thickness of the dome ranges from $3.00 \mathrm{~m}$ at the interface to $5.00 \mathrm{~m}$ at the crown. Concerning the original concept idealized by Michelangelo, the design of the dome was slightly modified by G. Dalla Porta. The curvature of the dome has been slightly changed to make it alike with the Florence domes designed by Brunelleschi. Two iron rings were also introduced, which revealed to be essential containing the structure after the damage occurred during the seismic event of 1703 [18]. After 50 years of its completion, some damage has been reported on the dome. By the mid-18th century, the latter damage was rather evident and, therefore, a survey was performed by L. Vanvitelli. It revealed that the drum and the attic were rotating outwards causing the onset of meridian cracks that lead to the split of the dome in several pushing arches. This is, from a structural standpoint, undesirable as these arches behave independently and the membrane effect is lost. In 1742, two reports published by three famous mathematicians [21] stated that Saint Peter's dome was seriously damaged and would require extensive straightening interventions. 


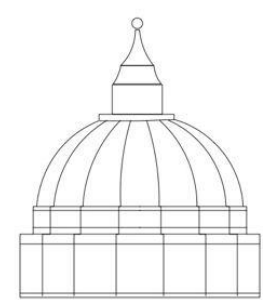

Michelangelo (1560)

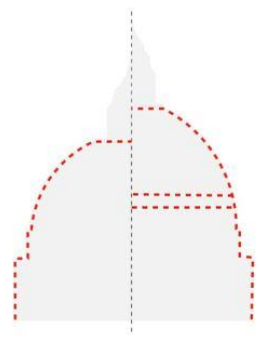

Parabolic profile

G. Dalla Porta (1592)

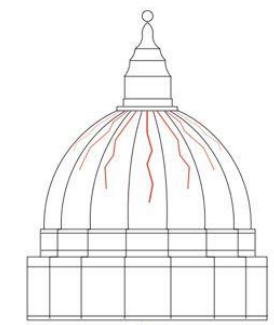

Whow

Seismic event of 1703

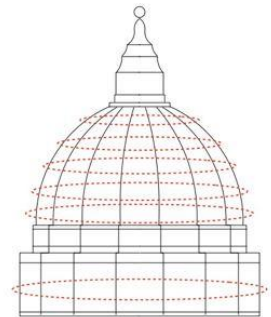

Strengthening interventions

G. Poleni (1743) 2020

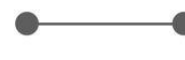

1564: death of Michelangelo
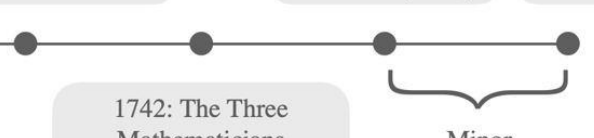

Mathematicians

formulate their theory

interventions

Figure 3: Timeline of the San Peter's dome.

The latter theory, the so-called "The Three Mathematicians" theory, was formulated based on a simple but ingenious model able to identify the thrust of the dome (Figure 4). While other scientists gave controversial opinions, Pope Benedict decided to follow the recommendations from another brilliant scholar, Giovanni Poleni [22]. Together with L. Vanvitelli, the researchers stated that Saint Peter's dome was adequately designed and proposed non-invasive
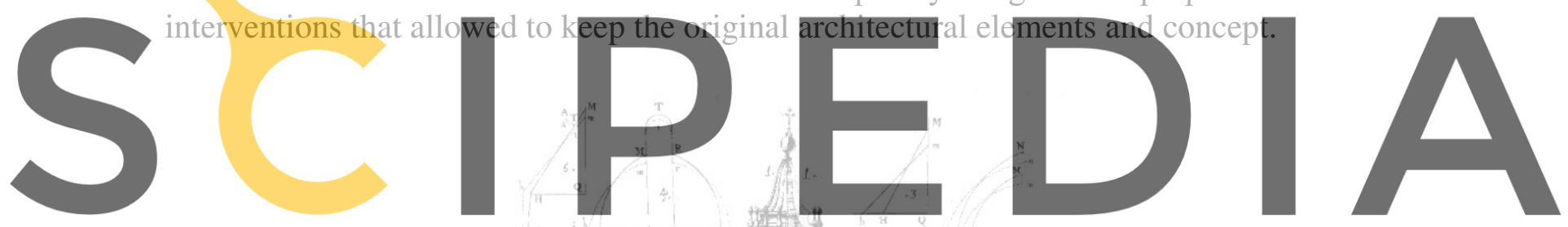

Register for free at https//www.scipedia.com to download the version without the watermark

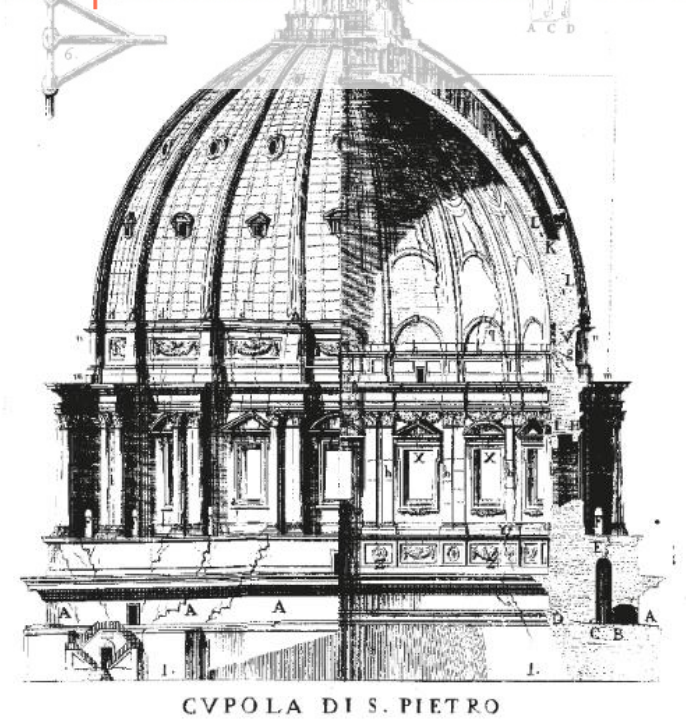

Figure 4: San Peter's dome: drawings presented by the so-called “The Three Mathematician”. 
The most crucial strengthening operation on the dome was encircled by six iron rings. Recently, it may be remarked that other researchers are trying to better understand the structural behaviour of Saint Peter's dome using advanced methods of diagnosis [23].

\section{RESULTS}

In this section, the structural safety assessment of San Peter's dome has been performed by adopting the digital tool described in Section 2. The main aim is to compute the horizontal thrust of the dome and verify the structural safety of the drum/attic/buttresses system. For that, the structural verification is performed considering the absence of the strengthening interventions designed by G. Poleni. (1743). Poleni [22] and M. Como [18] investigated the structural behaviour of the dome on a single 1/50 slice of the entire dome. Here, the parametric modelling of the dome allows us to consider a 1/16 slice of the dome (see Fig. 5). This is the most rational choice when considering the architectural geometry and its symmetry conditions (Fig. 5). After the parametric modelling of the dome, the second step consists of the evaluation of the minimum horizontal thrust of the dome and associated failure mechanism.

The failure mechanism depends of the rotational hinge $(h)$ position and the algorithm proposed is capable to incorporate the formulation of the PVW equation given in Eq. (1). The digitalization of the geometry allows us to instantly compute distances and to perform the integral calculus to evaluate the centroids' positions of the macroblocks and corresponding

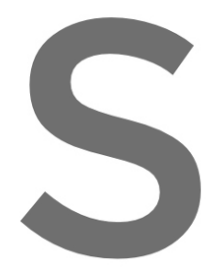
weights.

\section{Register for free at https//www.scipedia.com to download the version without the watermark}

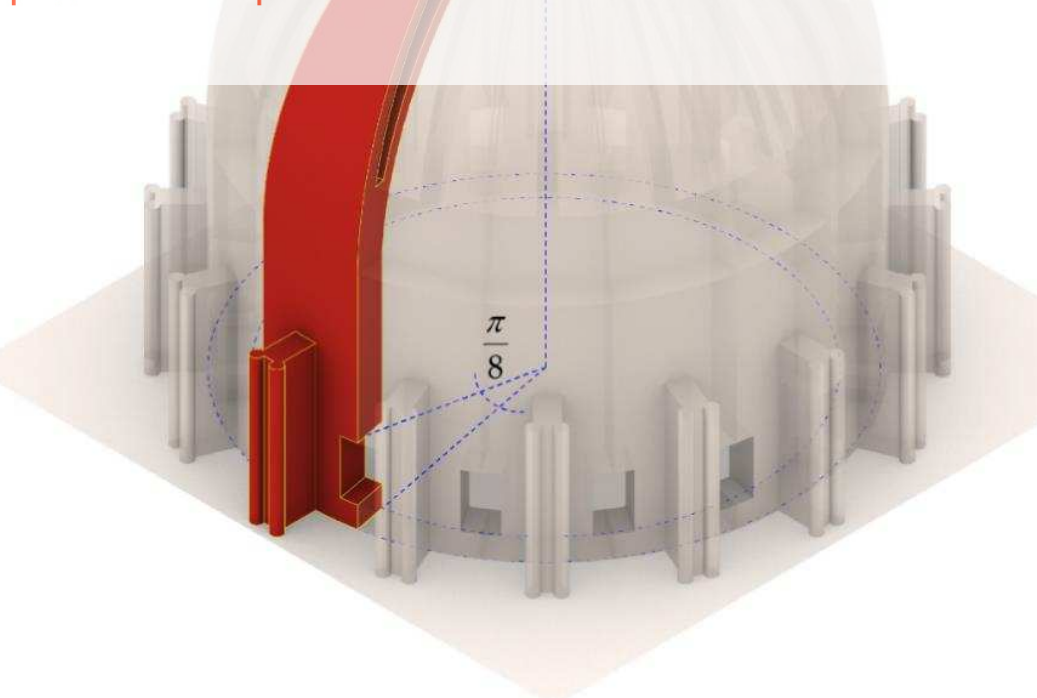

Figure 5: Representation of the $1 / 16^{\text {th }}$ slice of the dome. 
Table 1: Specific weight of the masonry and the lantern body force.

\begin{tabular}{ccc}
\hline Specific weight $\left[\mathrm{kN} \mathrm{m}^{-3}\right]$ & Lantern weight $[\mathrm{kN}]$ & Lantern weight $(1 / 16)[\mathrm{kN}]$ \\
\hline 18.50 & 14877 & 930 \\
\hline
\end{tabular}

Furthermore, the program integrates the capability to consider the work performed by other loads, as the lantern's weight. Table 1 shows the specific weight assigned for the masonry, as well as the lantern self-weight (note that the lantern has been simulated using its body force).

Once the minimum horizontal thrust is computed, the tool can verify the structural safety of the drum/attic/buttresses system. The user can set the position of the rotational hinge based on engineering considerations, i.e. the crack pattern that affects the buttresses. To compare the result with the one given by Como [18], the position of the rotational hinge is assumed to be at the interface between the drum and buttresses (Fig. 6a). The obtained results are in agreement with those obtained by Como [18] and are summarized in Table 2. Figure $6 \mathrm{~b}$ shows the capabilities of the proposed digital tool which shows the failure mechanism obtained in no time. Referring to a slice of $1 / 16$ of the dome, the horizontal thrust computed is equal to $2287 \mathrm{kN}$, whereas the vertical weight is equal to $12676 \mathrm{kN}$. Hence the structural efficiency of the San Peter's dome, defined as the ratio between the thrust and the weight of a single slice, is equal to 0.18 . The solver converges after few interactions, in $3 \mathrm{~s}$ with an Intel® ${ }^{\circledR}$ Core $^{\mathrm{TM}}$ i7-6700HQ.

Furthermore, it is worthy of mentioning that the modelling of the geometry has been conducted having the available drawings as a basis. However, a more detailed geometrical

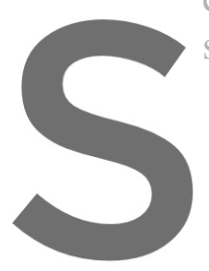
survey should be perfor
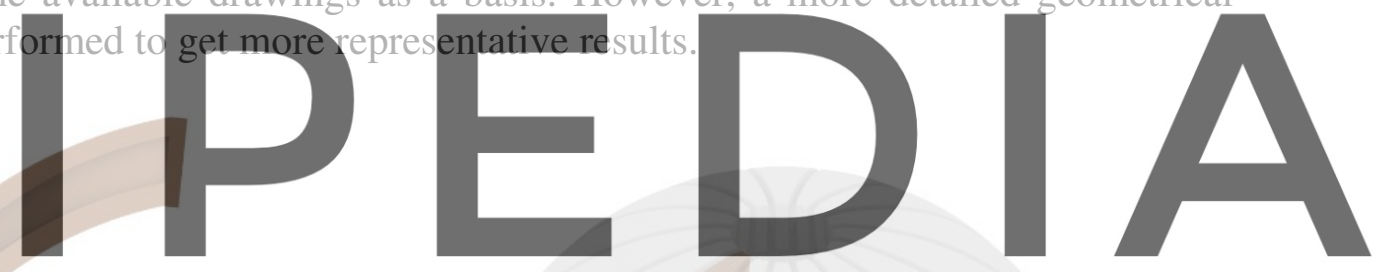

Register for free at https//www.scipedia.com to download the version without the watermark

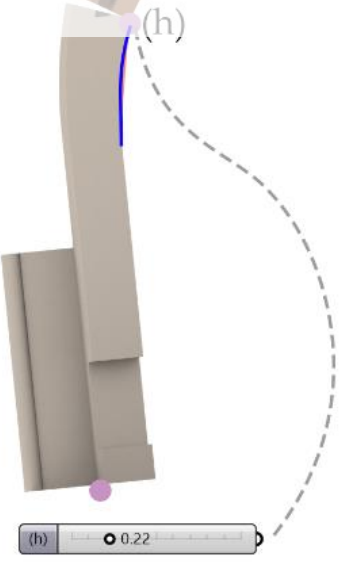

(a)

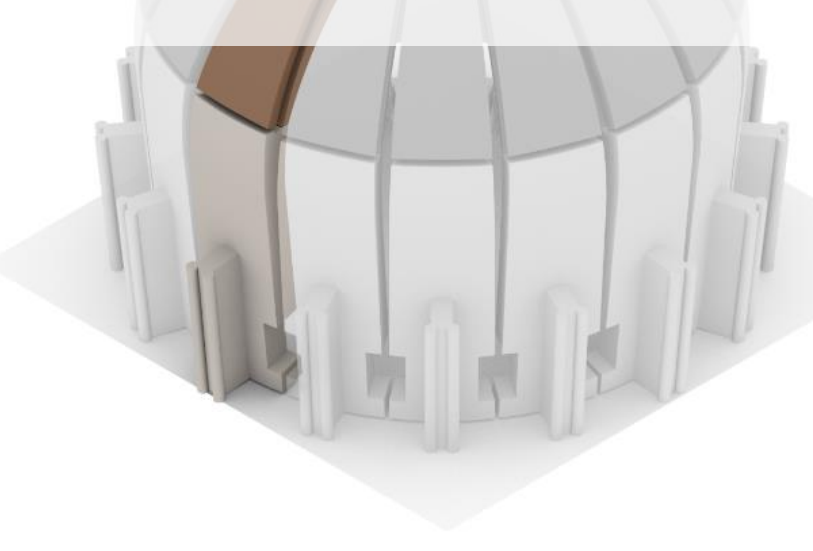

(b)

Figure 6: Obtained failure mechanism: (a) 1/16 slice of the dome; and (b) collapse mechanism of the entire dome. 
Table 2: Summary of the results.

\begin{tabular}{cccc}
\hline $\begin{array}{c}\text { Horizontal Thrust } \\
{\left[\mathrm{kN} \cdot \mathrm{m}^{-1}\right]}\end{array}$ & Dome efficiency [-] & $\begin{array}{c}\text { SF } \\
\text { drum/attic/buttresses } \\
{[-]}\end{array}$ & $\begin{array}{c}\text { Computational Time } \\
{[\mathrm{s}]}\end{array}$ \\
\hline 255.0 & & 1.08 & 3.00 \\
\hline
\end{tabular}

\section{CONCLUSIONS}

This work presents a digital tool for the structural assessment of historic masonry domes. The method embeds an upper bound limit analysis under a no-tension capacity hypothesis for the masonry material and an optimization scheme based on the Nelder-Mead method. The workflow is integrated within a user-friendly computational tool implemented in the visual programming environment offered by Rhinoceros3D+Grasshopper.

The numerical performance of the proposed methodology has been validated on the case study of San Peter's dome. According to Como's model, the proposed methods can evaluate the minimum horizontal thrust of the dome and properly find the geometry of the prone failure mechanism. Furthermore, the structural integrity of the system drum/attic is evaluated. The numerical result is in agreement with that obtained by Como. Unlike other more timeconsuming advanced methods of analysis, the proposed method allows the users to perform a structural assessment of historic masonry domes in a rapid and computationally efficient manner. Furthermore, the graphical visualizer allows us to give, in a direct way, the failure mechanism. The proposed visual script has been developed by using existing grasshopper components. However (ad-hoc programmed in available from a web ar the effect of the iron rings designed by G. behaviour of the San Peter's dome through advanced methods of analysis.

\section{Register forfree at https//www.scipedia.com to download the version without the watermark}

[1] Stepinac, M., et al., Methods for the assessment of critical properties in existing masonry structures under seismic loads-the ARES project. Applied Sciences (Switzerland), 2020. 10(5).

[2] Porter, D.W., et al., Material and seismic assessment of the great house at casa grande ruins national monument, arizona. Journal of Architectural Engineering, 2020. 26(1).

[3] Morici, M., et al., Empirical predictive model for seismic damage of historical churches. Bulletin of Earthquake Engineering, 2020. 18(13): p. 6015-6037.

[4] Olivito, R.S., et al. A numerical-geometrical methodology to represent out-of-plane mechanisms of unreinforced masonry structures by using pushover analysis. in COMPDYN Proceedings. 2019.

[5] Fortunato, G., Funari, M.F., and Lonetti, P., Survey and seismic vulnerability assessment of the Baptistery of San Giovanni in Tumba (Italy). Journal of Cultural Heritage, 2017. 26: p. 64-78.

[6] Savalle, N., Vincens, É., and Hans, S., Experimental and numerical studies on scaled-down dry-joint retaining walls: Pseudo-static approach to quantify the resistance of a dry- 
joint brick retaining wall. Bulletin of Earthquake Engineering, 2020. 18(2): p. 581606.

[7] Mehrotra, A., Arede, A., and DeJong, M.J., Discrete element modeling of a post-tensioned masonry arch. Civil-Comp Proceedings, 2015.

[8] Cascardi, A., et al. Structural analysis of a masonry church with variable cross-section dome. in Brick and Block Masonry-From Historical to Sustainable Masonry: Proceedings of the 17th International Brick/Block Masonry Conference (17thIB2MaC 2020), July 5-8, 2020, Kraków, Poland. 2020. CRC Press.

[9] Silva, L.C., et al., Seismic Structural Assessment of the Christchurch Catholic Basilica, New Zealand. Structures, 2018. 15: p. 115-130.

[10] Bacigalupo, A., Brencich, A., and Gambarotta, L., A simplified assessment of the dome and drum of the Basilica of S. Maria Assunta in Carignano in Genoa. Engineering Structures, 2013. 56: p. 749-765.

[11] Bartoli, G., Betti, M., and Borri, C., Numerical modeling of the structural behavior of Brunelleschi's Dome of Santa Maria del Fiore. International Journal of Architectural Heritage, 2015. 9(4): p. 408-429.

[12] Cavalagli, N. and Gusella, V., Dome of the basilica of santa maria degli angeli in Assisi: Static and dynamic assessment. International Journal of Architectural Heritage, 2015. 9(2): p. 157-175.

[13] Bretas, E.M., Lemos, J.V., and Lourenço, P.B., A DEM based tool for the safety analysis

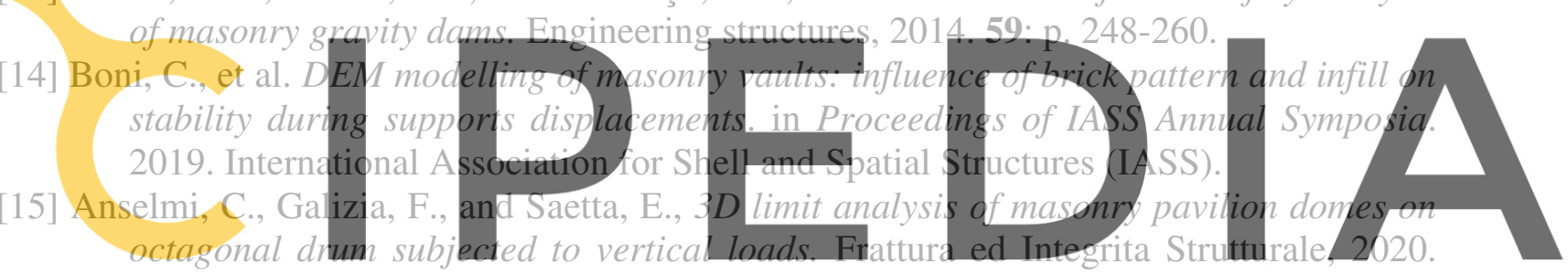
14(51): p. 486-503

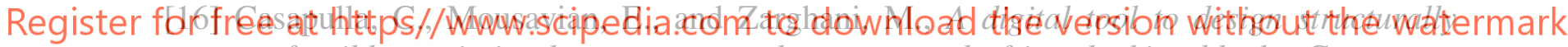
feasible semi-circular masonry arches composed of interlocking blocks. Computers and Structures, 2019. 221: p. 111-126.

[17] Funari, M.F., et al., Visual programming for structural assessment of out-of-plane mechanisms in historic masonry structures. Journal of Building Engineering, 2020. 31.

[18] Como, M., Statics of historic masonry constructions. Vol. 1. 2013: Springer.

[19] Feizolahbeigi, A., et al., Discussion of the role of geometry, proportion and construction techniques in the seismic behavior of 16th to 18th century bulbous discontinuous double shell domes in central Iran. Journal of Building Engineering, 2021. 33.

[20] Gregson, S., Nelder-Mead Optimisation (EOC), https://www.eocengineers.com/en/news/digital-design-group-tackles-classicengineering-problem 2018.

[21] Le Seur, T., Jacquier, F., and Boscovich, R., Parere di Tre Matematici Sopra i danni, che si sono trovati nella cupola di San Pietro sul fine dell'anno MDCCXLII. Dato per ordine di Nostro Signore Papa Benedetto XIV, Roma. 1742.

[22] Poleni, G., Memorie istoriche della gran cvpola [cupola] del tempio Vaticano, e de'danni di essa, e de'ristoramenti loro, divise in libri cinqve: Repr. der. Ausg. 1748. 1982: Intemac. 
[23] Baldrati, B., LA CUPOLA DELLA BASILICA DI SAN PIETRO IN VATICANO. IL CANTIERE E IL SISTEMA COSTRUTTIVO. 2009.
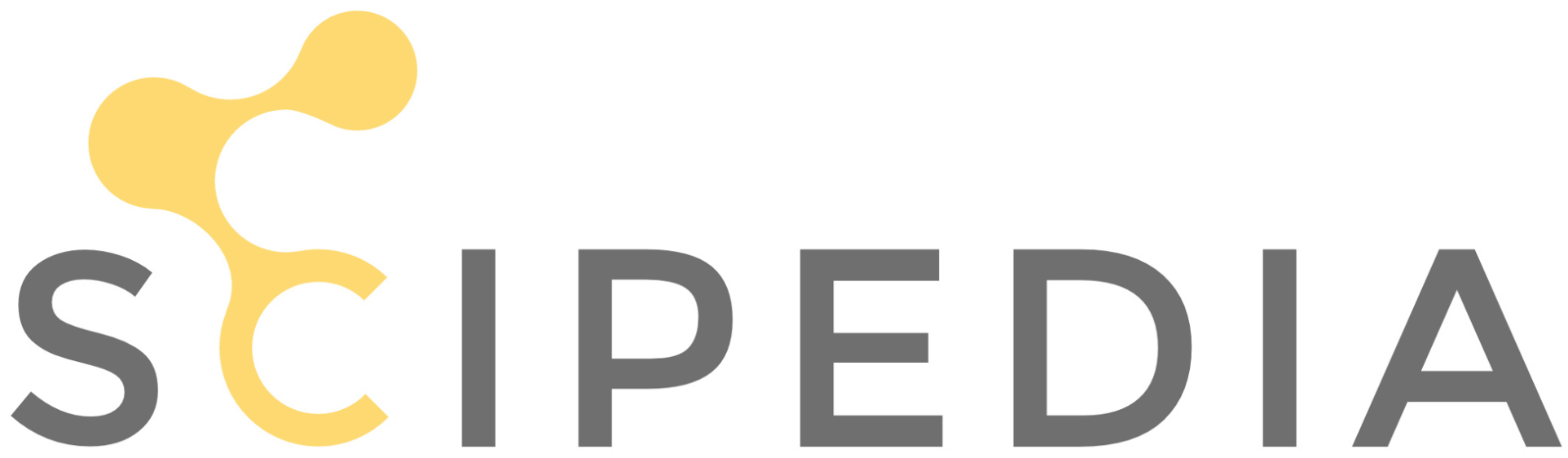

Register for free at https//www.scipedia.com to download the version without the watermark 